\title{
Forum
}

\section{Collision Risk with Fast Ferries}

\author{
Dag Pike
}

I. INTRODUCTION. Although fast ferries have been in operation for over 30 years they have been a relatively insignificant part of marine traffic, restricted to a few specific routes. Today, the growth in fast ferries is increasing on a rapidly expanding scale, not only in the density of traffic, but also in the size of the vessels. Speeds are also rising and the 5o-knot fast ferry is a reality, with even higher speeds on the drawing board and reaching the prototype stage. In 1995 , fast ferries of $140 \mathrm{~m}$ in length with speeds of 40 knots will be operating but, in the future, ocean-going cargo vessels of $200 \mathrm{~m}$ in length with a speed of 50 knots are projected, and wing-in-ground (wIG) passenger aircraft flying 5 or $10 \mathrm{~m}$ above the sea with speeds of 200 knots are already flying.

Whilst it is possible for fast passenger ferries operating on specific routes to be anticipated by other vessels, and their presence is sometimes indicated on the chart, encounters can still come as a surprise to larger, slower vessels. This and the more random nature of encounters with fast cargo vessels on ocean routes and the very high speeds of wig craft expose potential weaknesses and inadequacies in the International Regulations for the Prevention of Collision at Sea ${ }^{1}$ which could introduce a significant risk of collision through encounters between high speed craft and conventional vessels.

2. THE TIME FACTOR. The main principle of the current Regulations is that conflicting vessels should first see each other either visually or on radar, assess the collision risk and, if it exists, take any necessary avoiding action. The Regulations assume that there is the luxury of time to make the necessary identification and assess the risks. They also assume that vessels are adequately manoeuvrable to alter course in time or to slow down or stop.

In encounters between two fast ferries or between a fast ferry and a slower vessel, the luxury of time to make the necessary assessments and manoeuvres disappears rapidly. A fast ferry of, say, 50 knots may be sighted visually or on radar at a distance of 8 miles. This means that there can be less than Io minutes before a collision occurs if no action is taken. Allowing for the speed of the other vessel, which might be another fast vessel, means that this time could be halved. In that io minutes or less the slower vessel may travel less than 2 miles which, for a vessel such as a large tanker or bulk carrier, will not allow much time for reduction in speed and may not allow time to take avoiding action under steering alone.

The ro-minute time factor is generous, because at least 2 or 3 minutes will be taken up in making the collision risk assessment, and possibly a further minute coming to terms with the fact that the other vessel is travelling as fast as the radar indicates. So we could be faced with situations where large, slow vessels, once they have established that a collision risk exists, cannot take adequate avoiding action, because there is not adequate time.

3. ThE CURRENTREgulations. The current Collision Regulations allow for this 
situation under Rule 17 (b): 'When, from any cause, the vessel required to keep her course and speed finds herself so close that collision cannot be avoided by the action of the give-way vessel alone, she shall take such action as will best aid to avoid collision.'

That is fine, and in theory the fast vessel, even if it is the stand-on vessel, should appreciate the situation and also take avoiding action. However, with both vessels taking avoiding action, the collision risk could be compounded if each vessel does not anticipate the action of the other.

In practice, what happens with most encounters between fast and slow vessels is that the fast vessel, whether it is the give-way vessel or the stand-on vessel, makes the necessary alteration of course. In general, the current fleet of high speed craft are very manoeuvrable and easily able to take avoiding action, and there doesn' $t$ appear to be any evidence of any actual collisions occurring, although there have probably been a number of unreported near-misses.

With the advent of larger, faster vessels, the problem becomes more acute. These larger vessels will be less agile than the current vessels and the fact that they may be operating on less clearly defined routes could mean that the assessment of the collision risk by the slower vessel could take significantly longer. It has to be appreciated that the look-out and anticipation levels on any vessel tend to be geared towards the speed of that vessel rather than the speed of any possible approaching vessels. Anticipation levels on a fast vessel are generally high, but on a 12 knot ship they will be low.

It is not just large ships which may have difficulty in taking avoiding action from these fast vessels. They can pose a considerable threat to small craft, fishing vessels and yachts. The threat here comes in two forms - one from the short detection range of these small craft from the ferry, and the second from the potential inability of slow speed small craft to take effective avoiding action in time.

At night, a small craft may be detected either visually or by radar at ranges of under 2 miles. This means that when there is a collision risk, the time for avoiding action to be taken could be under 3 minutes and this time has to include the time required for assessment of the situation. As far as the small craft are concerned, they may be able to identify the fast craft at greater distances, but trying to assess a safe course of action may take longer and, at speeds of, say, 5 knots, the possible courses of action may be very limited. For fishing boats, hampered by their gear, avoiding action may be impossible.

So far we have only considered single vessel encounters, but the problems and risks can be increased in busy shipping channels where an alteration for one vessel can bring the fast vessel into conflict with another. In these conditions, passing distances can be greatly reduced with a consequent increase in risks. Risks will also inevitably increase at night and in poor visibility, and the latter conditions raise the question of what reduction in speed is required under Rules 6 and 19 of the Regulations and what is a 'safe speed'.

4. POSSIBLE SOLUTIONS. The main purpose of this paper is to raise an awareness of the potential inadequacy of the existing regulations to cope with the collision risks presented by the present and future generations of fast vessels. However, it is worth exploring some of the possible solutions:

(i) An easy solution would be to restrict the speed of fast ferries, demanding a reduction in speed to a 'safe speed' of, say, 30 knots immediately any potential collision risk situation is detected. Such a course of action would increase the time to the possible point of conflict but it would mean that a large number of ferry operations would be confined to this speed because, almost by definition, ferry routes tend to cross main shipping routes. 
(ii) There is much to be gained by putting the onus on the fast ferry to take avoiding action in all potential collision risk situations. They tend to be more manoeuvrable than conventional craft and, perhaps more important, their crews tend to be more alert to rapidly changing situations. Such action also closely complies with the current situation where fast vessels tend to take early avoiding action so that the other vessel has a clear and early indication of what is happening.

(iii) This situation could be regularized by allowing fast vessels to be the initiators of avoiding action in all circumstances, whilst the vessels involved are at least, say, 3 miles apart. Inside this distance both vessels must conform to the existing rules and the fast vessel must slow down to, say, 20 or 30 knots in order to give more time for avoidance action.

(iv) This ruling could also apply in the case of an encounter between a fast vessel and a slow, small craft, but such a ruling could lead to such small craft being banned from areas where fast vessels operate in order to remove the problem. Harbour authorities may want to exercise this power, and indeed should be encouraged to make special provisions for fast vessels, particularly ferries, in the waters they control to meet special circumstances; but banning craft from particular areas or giving precedence to certain types of craft is both unfair and difficult to enforce.

(v) In all cases it is important that faster craft, say those operating at over 30 knots, should be capable of being identified as such at an early stage of detection. Considerably brighter navigation lights would help and a special identification signal should be considered. Hovercraft already have such a signal - an orange flashing light - but that is to inform other shipping that their indicated course from their appearance may be widely different from their course over the ground. The use of flashing orange lights is spreading to other fast vessels in some harbour areas, notably Hong Kong and Singapore, but to be of value, any such signal should be internationally recognized. Another possibility is to have a radar transponder which produces a unique response on the radar display to indicate that the target is a fast vessel. Such a signal would be useful in poor visibility but it does not cover the situation where a fast vessel meets a small craft without radar.

(vi) For regular high speed ferry routes, it could be sensible to have all these marked on charts so that the mariner can have some warning of possible high speed encounters. However, the future points to these high speed craft operating on open ocean routes where it is less easy to anticipate where encounters may occur.

(vii) One of the difficulties in any change in the regulations will be to define what is a fast vessel. A small craft travelling at 40 knots does not pose much of a threat and self-preservation will lead to safe collision avoidance practices. A large vessel travelling at the same speed presents a clear risk, but where are the dividing lines to be drawn?

5. CONCLUSIONS. There is no easy solution to the problem of defining what is a fast vessel and solving the increasing problem of encounters between fast ferries and other slower vessels. It is suggested that these vessels currently present an unacceptable increase in the risk of collision at sea and that action is needed at this early stage in order to prevent the situation escalating to the point where collisions occur. Harbour authorities may see it as necessary to create special rules regarding speeds and priorities 
in the waters under their control but, for open sea routes, the International Regulations for the Prevention of Collision at Sea must provide the guidance and they need to be amended to take account of the technological development now taking place in the fast vessel market.

\title{
REFEREN CE
}

1 The International Regulations for the Prevention of Collision at Sea. International Maritime Organization 1972.

KEY WORDS

I. Collision avoidance. 2. Fast ferries.

\section{'Conflicts in Inshore Waters'}

\author{
A. T. C. Millns
}

I write in full support of Commander P. S. Booth, RN, and his excellent article on this subject. ${ }^{1}$

My own background is as a yachtsman since 1949 and as a professional, having obtained my Master's Certificate in 1963 . I have sailed the Solent both professionally and privately, under oars, sail and power, in vessels from dinghies, whalers, cruisers, a 6-metre, a 100 -ton ketch and passenger liners up to $780 \mathrm{ft}$ in length, with a draft of $32 \mathrm{ft}$ and a bridge height of eye of $95 \mathrm{ft}$. As a teenager I was originally taught how to sail by a seventy-year-old retired fisherman in Bosham. He made it very plain to me that he had no wish to get his feet wet, and yet taught me how to win races and cups in the local sailing club; that is, to be a safe sailor. The lecturers at the School of Navigation, University of Southampton had a similar aversion to wet feet and ensured that our boat and ship handling did not give rise to that catastrophe, whilst still being able to keep to a strict schedule. For years I departed from Southampton at $\mathrm{i} 600 \mathrm{hrs}$ and arrived off the Cape Town breakwater to pick up the pilot at 0606 precisely. All shipping movements in the harbour were held for our arrival.

Segregation already exists in other transport spheres such as airports. We do not find light aircraft taking off alongside intercontinental jets, and even in motorway service areas, commercial vehicles are segregated from cars.

I cannot understand the comments from the yachting fraternity. It is like a mother telling her child to cross the road in front of an approaching lorry, because 'he has got to stop for you, dear'. I am very concerned that a yachtmaster instructor should take the view expressed in the January 1995 Journal. ${ }^{2}$ This is not a new problem and was covered in the Collision Regulations brought into force by an Order in Council on I January I 954 - Rule 30 - Reservation of Rules for Harbours and Inland Navigation: 'Nothing in these Rules shall interfere with the operation of a special rule duly made by local authority relative to the navigation of any harbour, river, lake or inland water, including a reserved seaplane area.' I wonder how the modern Solent yachtsmen would react to the Princess Flying Boats - yachtsmen at the time handled the matter very well. I am sorry that this Rule is no longer included in the present Regulations since it gave a depth of perspective to all seagoers. Bringing Moyana, a 100-ton ketch, to her mooring in the Hamble involved at times signalling to comparatively small yachts to give way. They used to enjoy the extra space left by our vacant mooring in which to tack. Summer has always 